\title{
Preparation and Performance of a Fixed Bed Catalyst for the Oxidation of Sodium Mercaptides
}

\author{
Wang Heming, Liu Xianshang, Zhu Lijun, Zhou Yulu, Xia Daohong* \\ State Key Laboratory of Heavy Oil Processing, China University of Petroleum, \\ Qingdao, 266580, China
}

Received: 20th June 2013; Revised: 1st March 2014; Accepted: 22nd March 2014

\section{Abstract}

The activated-carbon supported cobalt pthalocyanine as a fixed bed catalyst (CoPc/C) was prepared by impregnation method and its performance on the oxidation of sodium mercaptides in light oil sweetening was investigated. The FTIR, XRD and SEM analysis indicated that the active component dispersed well on the carrier and the results of the TG analysis showed that $\mathrm{CoPc} / \mathrm{C}$ has good thermostability. It was tested that the prepared catalyst has a high catalytic activity towards sodium mercaptides. The removal rate of $\mathrm{n}$ $\mathrm{C}_{4} \mathrm{H}_{9} \mathrm{SNa}$ was up to $100 \%$ and for $\mathrm{t}-\mathrm{C}_{4} \mathrm{H}_{9} \mathrm{SNa}$, was $87.5 \%$ at a reaction time of $30 \mathrm{~min}$. With the reaction temperature raised from $20^{\circ} \mathrm{C}$ to $60{ }^{\circ} \mathrm{C}$ at intervals of ten degrees, the oxidation rate increased obviously, especially in the first ten minutes. A kinetic model mainly related to the transfer process was supposed. The catalyst $\mathrm{CoPc} / \mathrm{C}$ had a good anti-loss performance of the active component both in water and alkali liquor when used. (C) 2014 BCREC UNDIP. All rights reserved

Keywords: fixed bed catalyst; sweetening; oxidation; sodium mercaptide; light oil

How to Cite: Heming, W., Xianshang, L., Lijun, Z., Yulu, Z., Daohong, X., (2014). Preparation and performance of a fixed bed catalyst for the oxidation of sodium mercaptides. Bulletin of Chemical Reaction Engineering \& Catalysis, 9 (2): 87-92. (doi:10.9767/bcrec.9.2.5113.87-92)

Permalink/DOI: http://dx.doi.org/10.9767/bcrec.9.2.5113.87-92

\section{Introduction}

Caustic extraction is a widely used method for the removal of thiols in light oil because the low molecular weight mercaptans are very soluble in the caustic solution[1,2]. Then the caustic solution would be regenerated by a catalytic oxidation process. Phthalocyanines of the metals like cobalt, iron, nickel and vanadium are a sort of catalysts used in this process[3], especially the cobalt Phthalocyanine and its derivatives[4, 5]. However, the previous researches are mainly concentrated in the liquor-liquor reaction[6] or making the catalyst into slurry[7], which could reduce the activity of the catalyst because the dimerization and loss of cobalt

* Corresponding Author.

E-mail: xiadh@upc.edu.cn (Daohong, X.) Fax: +86-532-86981869 phthalocyanine when it is used [8].

Here, we proposed to fix the cobalt phthalocyanine on a carrier and make it as a fixed bed catalyst for the regeneration of alkali liquor. The selected carrier is activated carbon and our investigation is focused on the preparation and performance of this catalyst $(\mathrm{CoPc} / \mathrm{C})$.

\section{Materials and Methods}

\subsection{Materials}

A mixture of $200 \mathrm{ml} 10$ wt.\% $\mathrm{NaOH}$ solution with calculated volume mercaptan in a $250 \mathrm{ml}$ conical flask was stirred for 15 min under the protection of $\mathrm{N}_{2}$ at room temperature. Then 40 $\mathrm{ml}$ petroleum ether was added to the reaction mixture and stirred continuously for another $15 \mathrm{~min}$. After that the mixture was transferred to a separating funnel and the sodium mercap- 
tide (RSNa) solution was separated into a conical flask and protected with $\mathrm{N}_{2}$. The concentration of sodium mercaptide was measured by titration before use.

\subsection{Catalyst preparation and characteri- zation}

$\mathrm{CoPc} / \mathrm{C}$ was prepared by the impregnation method. First, a $0.25 \mathrm{~g}$ cobalt phthalocyanine catalyst was dissolved in $100 \mathrm{ml}$ solvent mixed with 28 wt.\% ammonia and DMF, with a volume radio of $6: 1$. Second, $50 \mathrm{~g}$ of carbon that had been activated at $180{ }^{\circ} \mathrm{C}$ for $10 \mathrm{~h}$ was added to the mixture and impregnated for $24 \mathrm{~h}$. Lastly, the immobilization catalyst was filtrated out and dried at $120^{\circ} \mathrm{C}$ for $5 \mathrm{~h}$ [9].

$\mathrm{CoPc} / \mathrm{C}$ was characterized by FTIR, SEM, XRD and TG. SEM images were obtained with a Hitachi, X-650 scanning electron microscope $(20 \mathrm{kV})$. The FTIR spectrums of $\mathrm{CoPc} / \mathrm{C}$, the active component and the carrier respectively were measured with the Nicolet FTIR Fourier transform infrared spectrometer. The scanning wavelength was from $100-4000 \mathrm{~cm}^{-1}$ and the resolution was $4 \mathrm{~cm}^{-1}$. XRD patterns were obtained with a XRD-6000 Diffractometer equipped with CuKá radiation $(40 \mathrm{kV}, 30 \mathrm{~mA})$. The $2 \theta$ scanning angle range was $10-70^{\circ}$ with a step of $4 \% \mathrm{~min}$. A TG analysis was carried out in a WCT-2 thermobalance. About $10 \mathrm{mg}$ of catalyst was loaded and the airflow of $\mathrm{N}_{2}$ was $50 \mathrm{ml} / \mathrm{min}$. The heating rate was $15^{\circ} \mathrm{C} / \mathrm{min}$ and the final temperature was $679^{\circ} \mathrm{C}$.

\subsection{Catalytic tests}

Reactions were carried out in a $50 \mathrm{ml}$ flask that was equipped with a magnetic stirrer. In a

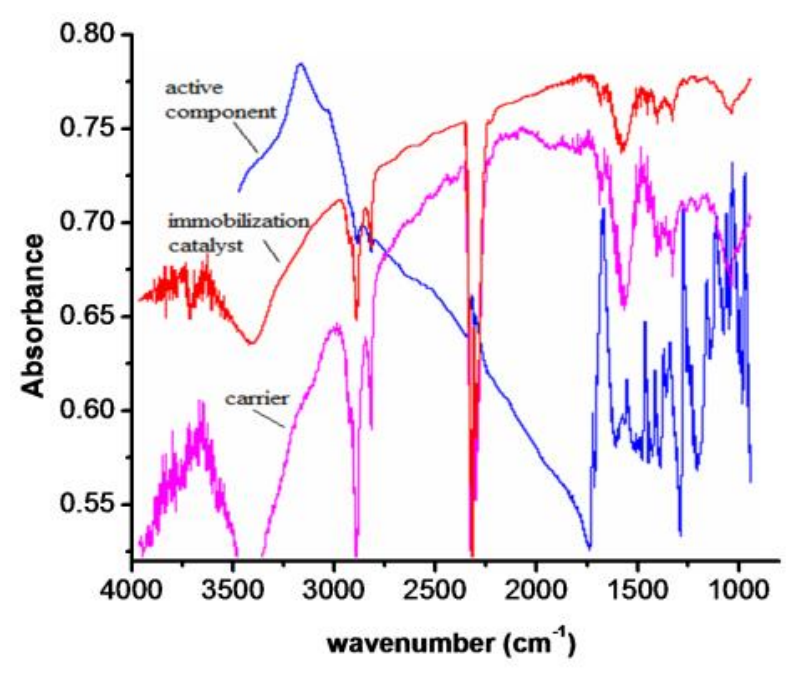

Figure 1. FTIR spectrums of $\mathrm{CoPc} / \mathrm{C}$, active component and carrier typical run, a mixture consisting of sodium mercaptide solution $(30 \mathrm{ml})$ and the catalyst $(0.5 \mathrm{~g})$ was stirred under an oxygen atmosphere in a water bath with a $30{ }^{\circ} \mathrm{C}$ temperature for $30 \mathrm{~min}$. Samples of the reaction mixture $(1 \mathrm{ml})$ were periodically withdrawn every $6 \mathrm{~min}$. The RSNa concentration was measured by standard potentiometric titration. The activity of the fixed bed catalyst was determined by the conversion rate of RSNa.

\section{Results and Discussion}

\subsection{Characterization of Catalyst}

The FTIR analysis results of $\mathrm{CoPc} / \mathrm{C}$, active component and carrier are shown in Figure 1. Figure 2 is the XRD analysis results of the activated carbon and $\mathrm{CoP} / \mathrm{C}$.

Figure 1 shows that the absorptions of the immobilization catalyst are very similar to that of the carrier as they are all in the wavenumber range of $1000 \mathrm{~cm}^{-1}$ to $4000 \mathrm{~cm}^{-1}$ and the active component of cobalt phthalocyanine in catalyst is not showing strongly absorption, as it is independently in the wavenumber range of $1000 \mathrm{~cm}^{-1}$ to $2400 \mathrm{~cm}^{-1}$. The results indicate that the active component entered the inner pores of the carrier during the catalyst preparation with impregnation and did not disperse on the outside surface of the carrier.

Figure 2 shows that the carrier diffraction line was very wide. The diffraction peaks appear at the $2 \theta$ angles $20-30^{\circ}$ and $40-48^{\circ}$, which were (002) (100) on the crystal face of the graphite structure surface. This is considered to be the result of the irregular arrangement of the graphite subtle crystal and the carrier is being in the form of microcrystalline carbon with an amorphous structure. The characteristic spectral line of the carrier was not found in

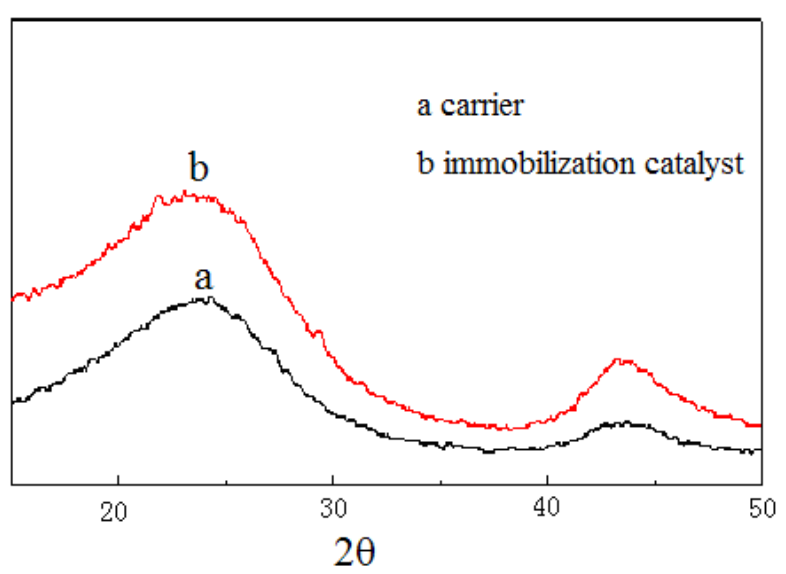

Figure 2. X-ray diffraction patterns of carrier and immobilization catalyst 
the diffraction patterns, since various matted crystal networks and micro-crystalline formed in the process of carbonizing crude materials such as fiber. The XRD patterns of the immobilization catalyst were the same as that of the carrier and no diffraction peaks of the cobalt phthalocyanine appeared, indicating that the catalyst active component was well dispersed on the carrier. This is consistent with the FTIR analysis results presented in Figure 1.

Figure 3 and Figure 4 are the images of $\mathrm{SEM}$ analysis of $\mathrm{CoPc} / \mathrm{C}$. The results in Figure 3 and Figure 4 prove that the active component dispersed well on the carrier and entered the inner pores of carrier because the particles of active component could not be observed on the outside surface of the catalyst (Figure 3), but could be observed in the inner pores after the catalyst was cut into slices parallel to the direction of the pores (Figure 4).

The TG results of $\mathrm{CoPc} / \mathrm{C}$ are listed in Table 1 . It can be seen that when it was heated from $20{ }^{\circ} \mathrm{C}$ to $190{ }^{\circ} \mathrm{C}$, the weight loss was $5.31 \%$, which can obviously be attributed to the removal of the water molecules absorbed on the catalyst. When it was further heated (from 192 ${ }^{\circ} \mathrm{C}$ to $525{ }^{\circ} \mathrm{C}$, and from $525{ }^{\circ} \mathrm{C}$ to $679^{\circ} \mathrm{C}$ ) the weight loss of the catalyst was $5.11 \%$ and 3.11 $\%$ respectively, which was due to functional groups such as the carboxyl and hydroxyl

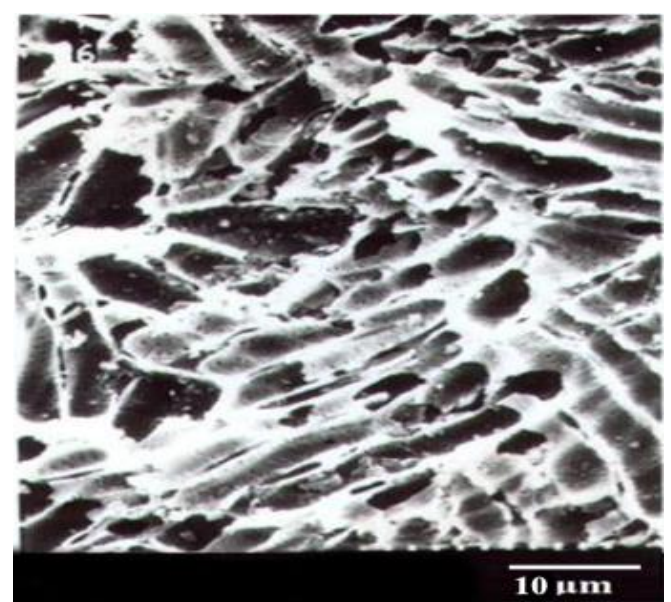

Figure 3. SEM of $\mathrm{CoPc} / \mathrm{C}$ with enlarged six hundred times

Table 1. Thermogravimetric analysis of catalyst

\begin{tabular}{cc}
\hline The temperature range $\left({ }^{\circ} \mathbf{C}\right)$ & weight loss (\%) \\
\hline $20-190$ & 5.31 \\
$192-525$ & 5.11 \\
$525-679$ & 3.11 \\
\hline
\end{tabular}

groups on the surface of the active carbon falling off at high temperatures. These results confirm the reported conclusion that the skeleton structure of the phthalocyanine has great stability [10, 11]. The TG results also reveal that the prepared catalyst has good stability.

\subsection{Catalytic tests}

\subsubsection{Catalytic oxidation of different con- centrations of sodium mercaptide}

The activity of the catalyst was evaluated by studying $\mathrm{RSNa}$ oxidation reaction using $\mathrm{n}$ $\mathrm{C}_{4} \mathrm{H}_{9} \mathrm{SNa}$ and $\mathrm{t}-\mathrm{C}_{4} \mathrm{H}_{9} \mathrm{SNa}$ as model compounds. The removal rate of sodium mercaptide sulfur might have been affected by the concentration of RSNa. In general, the higher the concentration of sodium mercaptide sulfur, the lower the oxidative removal rate of RSNa. The conversion of $\mathrm{n}-\mathrm{C}_{4} \mathrm{H}_{9} \mathrm{SNa}$ was investigated with the different starting concentrations of $100 \mu \mathrm{g} / \mathrm{g}, 200$ $\mu \mathrm{g} / \mathrm{g}, 300 \mu \mathrm{g} / \mathrm{g}, 400 \mu \mathrm{g} / \mathrm{g}$, and $500 \mu \mathrm{g} / \mathrm{g}$, respectively. The effect of the catalyst on the removal of $\mathrm{n}-\mathrm{C}_{4} \mathrm{H}_{9} \mathrm{SNa}$ was determined by following method 2.3, while the results are shown in Figure 5 .

Figure 5 shows that the catalyst had high removal efficiency for different concentrations of sodium n-butyl mercaptide sulfur. The removal rate of $\mathrm{n}-\mathrm{C}_{4} \mathrm{H}_{9} \mathrm{SNa}$ was $100 \%$ (concentration from $100 \mu \mathrm{g} / \mathrm{g}$ to $400 \mu \mathrm{g} / \mathrm{g}$ ) at the reaction time of $35 \mathrm{~min}$. For higher concentrations of $\mathrm{n}-\mathrm{C}_{4} \mathrm{H}_{9} \mathrm{SNa}(500 \mathrm{\mu g} / \mathrm{g})$, the removal rate was up to $92 \%$ at the same reaction time.

\subsubsection{Oxidation of different kinds of so- dium mercaptide}

The removal effect of the catalyst for different kinds of $\mathrm{RSNa}$, including $\mathrm{n}-\mathrm{C}_{4} \mathrm{H}_{9} \mathrm{SNa}$ and $\mathrm{t}$ -

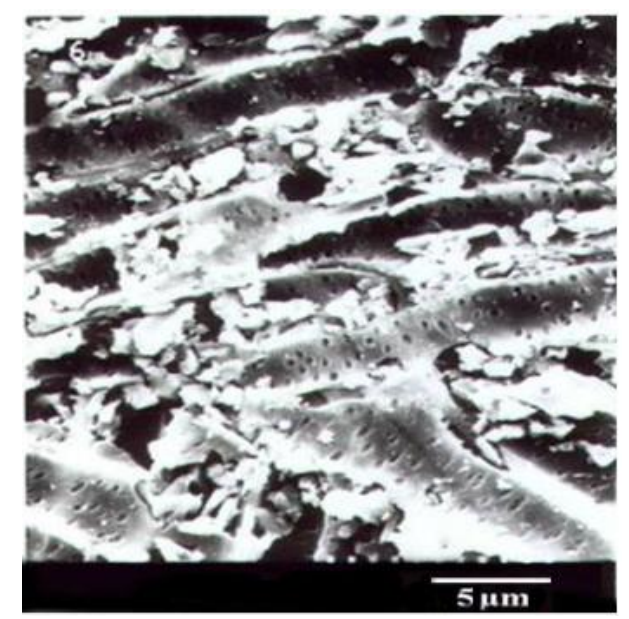

Figure 4. SEM of $\mathrm{CoPc} / \mathrm{C}$ with enlarged twelve hundred times 
$\mathrm{C}_{4} \mathrm{H}_{9} \mathrm{SNa}$, was investigated. The concentrations of RSNa are both and the observed results are presented in Figure 6.

Figure 6 shows that $\mathrm{CoPc} / \mathrm{C}$ has a high removal efficiency for different kinds of RSNa. The $n-\mathrm{C}_{4} \mathrm{H}_{9} \mathrm{SNa}$ could be reduced completely in the reaction and the removal rate of $\mathrm{t}-\mathrm{C}_{4} \mathrm{H}_{9} \mathrm{SNa}$ was up to $87.5 \%$ at a reaction time of $30 \mathrm{~min}$. The figure reflects that the $\mathrm{t}-\mathrm{C}_{4} \mathrm{H}_{9} \mathrm{SNa}$ underwent a slower oxidation than $\mathrm{n}-\mathrm{C}_{4} \mathrm{H}_{9} \mathrm{SNa}$. The results in Figure 5 and Figure 6 demonstrate that the immobilization catalyst is an effective catalyst for the oxidation of sodium mercaptide.

\subsubsection{Effect of Temperature}

The effect of temperature on the conversion of $\mathrm{RSNa}$ was studied. The $\mathrm{n}-\mathrm{C}_{4} \mathrm{H}_{9} \mathrm{SNa}$ was chosen as the model compound to be oxidized at the different reaction temperatures of $20^{\circ} \mathrm{C}, 30$ ${ }^{\circ} \mathrm{C}, 40{ }^{\circ} \mathrm{C}, 50{ }^{\circ} \mathrm{C}$, and $60{ }^{\circ} \mathrm{C}$. The concentration of $\mathrm{n}-\mathrm{C}_{4} \mathrm{H}_{9} \mathrm{SNa}$ was $100 \mathrm{\mu g} / \mathrm{g}$. The results are shown in Figure 7.

From Figure 7, it can be seen that the temperature had an obvious influence on the removal rate of $\mathrm{n}-\mathrm{C}_{4} \mathrm{H}_{9} \mathrm{SNa}$. Desulphurization rates were accelerated by increasing the reaction temperature. At the temperature of $60{ }^{\circ} \mathrm{C}$, the conversion rate of $\mathrm{n}-\mathrm{C}_{4} \mathrm{H}_{9} \mathrm{SNa}$ was up to $82.26 \%$ at the reaction time of 6 minutes. However it was only $46.78 \%$ at the temperature of $20{ }^{\circ} \mathrm{C}$. When the reaction time was extended to 30 min, n- $\mathrm{C}_{4} \mathrm{H}_{9} \mathrm{SNa}$ was removed completely at all the temperatures tested, excepting $20{ }^{\circ} \mathrm{C}$ (the removal rate was $96.78 \%$ ). The temperature increases sped up the movement of the sodium mercaptide molecules in the solution, making it easier for them to shift to the surface of the catalyst and make contact with active components, and finally increased the oxidation

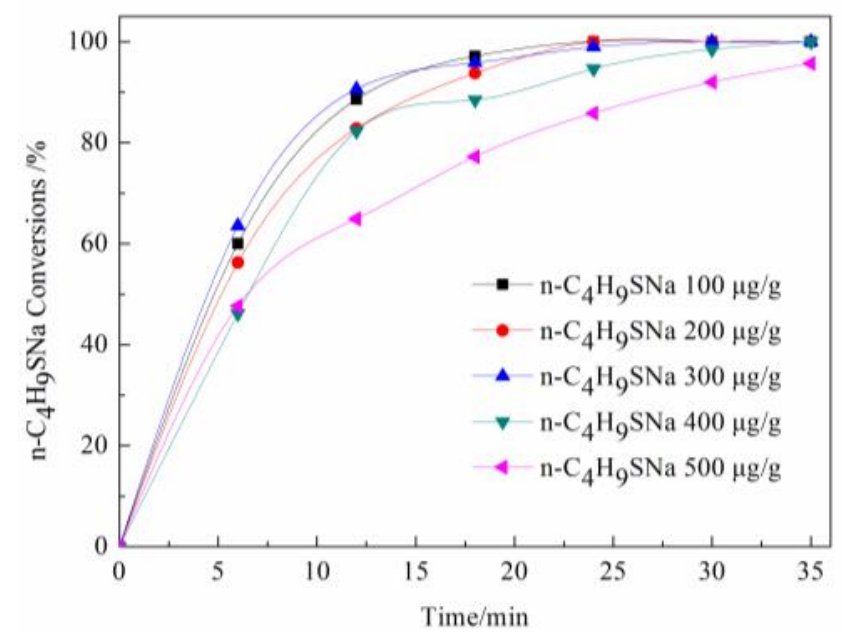

Figure 5. Effects of concentrations on conversions of $n-\mathrm{C}_{4} \mathrm{H}_{9} \mathrm{SNa}$ of RSNa.

\subsubsection{Anti-loss Performance of CoPc/C}

In an industrial application of the fixed bed catalyst, it will be loaded in the reactor bed and the caustic solution containing sodium mercaptide is passed over the fixed bed catalyst and regenerated. The catalyst must have a good anti-loss performance of the active components in water or in alkali liquor since it will be used for a long time. In order to demonstrate the anti-loss performance of the active components on the fixed bed catalyst, the catalyst was washed by water or caustic solution in the laboratory in order to simulate the industrial operation. A mixture consisting of water or 10 wt.\% $\mathrm{NaOH}$ solution $(20 \mathrm{ml})$ and the catalyst (1 g) was stirred vigorously for $20 \mathrm{~min}$ in a flask placed in a water bath at a temperature of 25 ${ }^{\circ} \mathrm{C}$.

Then the filtrate was separated and analyzed by the UV-vis spectrophotometry. The scan wavelength was from $900 \mathrm{~nm}$ to $200 \mathrm{~nm}$. If large absorption bands in the range of 600$700 \mathrm{~nm}$ appeared in the UV spectra of the filtrate, it indicated that some active components of the catalyst were washed off by water or 10 wt.\% $\mathrm{NaOH}$ solution $[12,13]$. For comparison, the Uv-vis spectrophotometry of the solution of cobalt phthalocyanine was also made. All the results are listed in Figure 8.

The results plotted in Figure 8 show that there were no UV-vis absorption peaks in the range of 600-700 for filtrates of water or caustic washing (plot A and B). On the contrary, obvious absorption peaks of active components of a cobalt phthalocyanine solution were detected (plot $\mathrm{C}$ ). This indicated that no active compo-

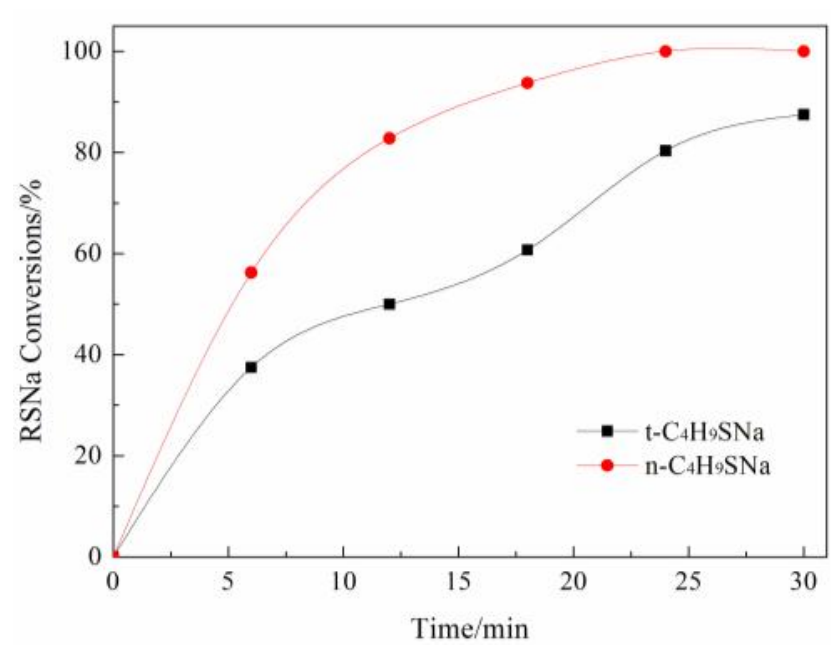

Figure 6. The removal effect of Catalyst for different kinds of $\mathrm{RSNa}$ 
nent was lost from the fixed bed catalyst after washed vigorously by water or caustic.

\subsection{Mechanistic Kinetics}

To interpret the observed behavior of oxidation rate curves of thiols, an anion-radical mechanism was put forward by Wallace et al. [14]. It was assumed that the thiols transferred into alkali liquor in the form of thiolate anions during the extraction operation and then the thiolate anions were oxidized into disulfides by $\mathrm{O}_{2}$ in the presence of CoPc. The specific process can be summarized as the following steps:

$$
\begin{aligned}
& \mathrm{RSNa} \rightleftharpoons \mathrm{RS}^{-}+\mathrm{Na}^{+} \\
& 2 \mathrm{Co}^{2+}+\mathrm{O}_{2}=2 \mathrm{Co}^{3+}+\mathrm{O}_{2}{ }^{2-} \\
& \mathrm{RS}^{-}+\mathrm{Co}^{3+}=\mathrm{Co}^{2+}+\mathrm{RS}^{*} \\
& 2 \mathrm{RS}^{*} \longrightarrow \mathrm{RSSR} \\
& \mathrm{O}_{2}{ }^{2-}+\mathrm{H}_{2} \mathrm{O} \longrightarrow 2 \mathrm{OH}^{-}+1 / 2 \mathrm{O}_{2}
\end{aligned}
$$

Overall reaction:

$\mathrm{RSNa}+\mathrm{O}_{2}+\mathrm{H}_{2} \mathrm{O} \longrightarrow \mathrm{RSSR}+\mathrm{NaOH}$

The intrinsic kinetics of thiolate anions oxidation was also reported to make further investigation to the rate law and the kinetic parameters and equations were estimated with the kinetic model of 1-butanethiol oxidation [15]. Nevertheless, when the catalyst was supported on the carriers, the formulated equations were not suitable since transfer process became an inconvenient factor to the reaction with different kinds of thiolate anions. A sketchy macroscopic mechanism mainly related to the trans-

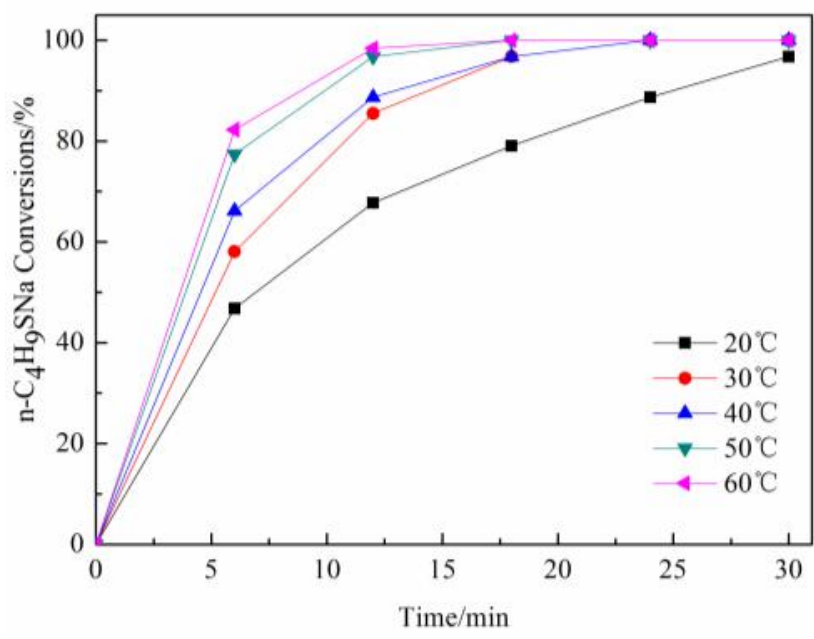

Figure 7. Effect of temperature on conversions of $\mathrm{n}-\mathrm{C}_{4} \mathrm{H}_{9} \mathrm{SNa}$ fer of reactants and products was proposed in Figure 9.

As it is shown in Figure 9, the CoPc molecules disperse well in the pores of the carrier and thiolate anions are adsorbed when they diffuse to the surface of the catalyst. Then thiolate anions enter the pores and in this process, one of them may meet with a $\mathrm{CoPc}$ molecule and a series of reactions ((3-1)-(3-6)) listed above will occur with the participation of oxygen adsorbed previously. Diffusion resistance and Steric hindrance should be taken into consideration under this condition, which was different from intrinsic kinetics. The structure of $n-\mathrm{C}_{4} \mathrm{H}_{9} \mathrm{SNa}$ is straight chain and this makes it easy to get in and out of the pores of catalyst. Whereas the $t$ $\mathrm{C}_{4} \mathrm{H}_{9} \mathrm{SNa}$ owns a larger space for it has a branch linked to the main chain, which is an obstacle for the diffuse of thiolate anions in the pores. Thus the model gives a reason why the oxidation rate of $\mathrm{t}-\mathrm{C}_{4} \mathrm{H}_{9} \mathrm{SNa}$ was lower than that of $\mathrm{n}-\mathrm{C}_{4} \mathrm{H}_{9} \mathrm{SNa}$ in the same conditions.

\section{Conclusions}

The characterization results of $\mathrm{CoPc} / \mathrm{C}$ indicate that $\mathrm{CoPc}$ disperses well in activated carbon. The $\mathrm{n}-\mathrm{C}_{4} \mathrm{H}_{9} \mathrm{SNa}$ was able to be reduced completely in the reaction and the removal rate of $\mathrm{t}-\mathrm{C}_{4} \mathrm{H}_{9} \mathrm{SNa}$ was up to $87.5 \%$ at a reaction time of $30 \mathrm{~min}$. Temperature of $50-60{ }^{\circ} \mathrm{C}$ for mercaptide oxidization is the optimum value. The anti-loss experiment show the stability of $\mathrm{CoPc} / \mathrm{C}$ when it is used. A sketchy macroscopic

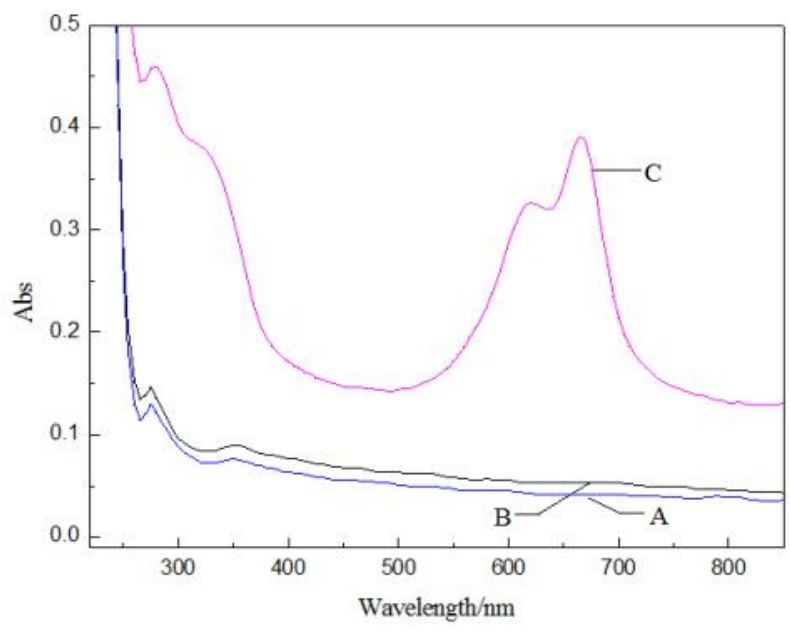

Figure 8. UV-Vis spectrum of water and caustic washing liquid for immobilization catalyst A-water washing liquid of immobilization catalyst, B- caustic washing liquid of immobilization catalyst, C- solution of cobalt phthalocyanine $(5 \mu \mathrm{g} / \mathrm{g})$ 


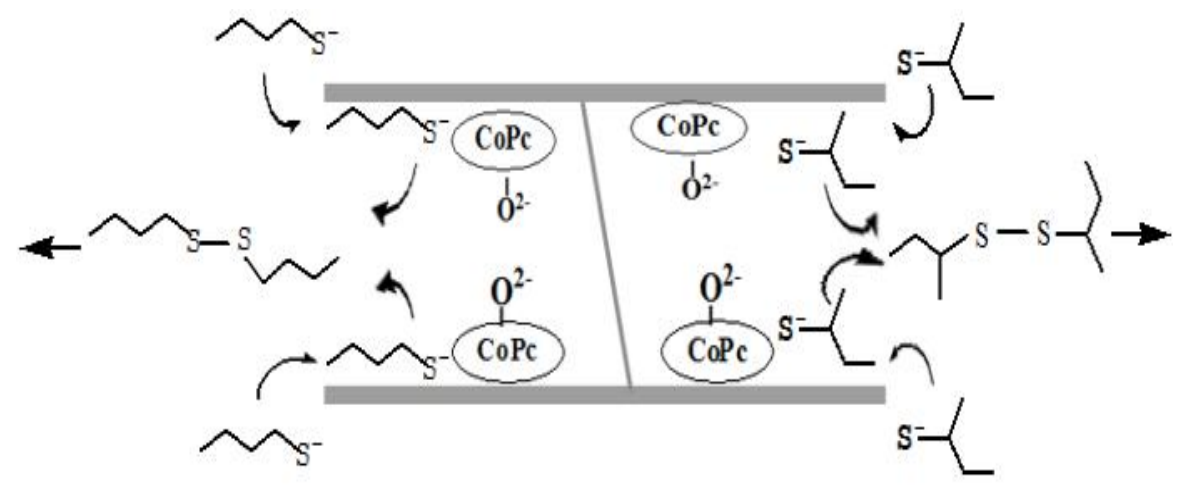

Figure 9. The transfer and reaction of thiolate anions in the pore of the catalyst

mechanism mainly related to the transfer theory was also proposed.

\section{Acknowledgments}

Authors are thankful for the State Key Laboratory of Heavy Oil Processing, China University of Petroleum, Qingdao, 266580, China for providing laboratory facilities.

\section{References}

[1] Jeffery, C.B., Luigi, L. (2012). Advances in Merox $^{\mathrm{TM}}$ Process and Catalysis for Thiol Oxidation. Top Catal., 55: 1315-1323.

[2] Liu, Z.N., Wang, H., Li, Y.G. (2002). Application of Fiber Film Desulfurization Technology for Resid FCC Naphtha Sweetening. Petroleum Processing and Petrochemicals, 33: 5-9 (in Chinese)

[3] Gangulya, S.K., Dasa, G., Kumarb, G., Kumar, S., Sain, B., Garg, M.O. (2013). Catalytic Oxidation of Mercaptans in Light Oil Sweetening: Kinetics and Reactor Design. Chemical Engineering, 32: 661-666.

[4] Wöhrle, D., Buck, T., Schneider, G., SchulzEkloff, G., Fischer, H. (1991). Low molecular weight, polymeric, and covalently bound cobalt(II)-phthalocyanines for the oxidation of mercaptans. J. Inorg. Organomet. Polym., 1: 115-130.

[5] Sun, Z.Y., Jin, L., He, S., Zhao, Y.F., Wei, M., Evans, D.G., Duan, X. (2012). A structured catalyst based on cobalt phthalocyanine/calcined $\mathrm{Mg}$-Al hydrotalcite film for the oxidation of mercaptan. Green Chem., 14: 1909-1916.

[6] Frame, R.R. (1981). US Patent No. 4,290,913. Washington, DC: U.S. Patent and Trademark Office.

[7] Das, G., Sain, B., Kumar, S., Grag, M.O., Dhar, G.M. (2009). Synthesis, characterization and catalytic activity of cobalt phthaloc- yanine tetrasulphonamide in sweetening of LPG. Catal. Today, 141: 152-156.

[8] Yu, H., Li, X.H., Xia, D.H., Xiang, Y.Z. (2007). Study on the stability of sulphonated cobalt phthalo- cyanine catalyst for sweetening process. Petroleum Processing and Petrochemicals, 38: 6-9 (in Chinese)

[9] Liu, M.X., Shi, M.D., Guan, Z.J., Si, X.Q., Zhou, Y.L., Xiang, Y.Z., Xia, D.H (2010). Study on performance of fixed bed sweetening catalyst for FCC naphtha. Petroleum Refinery Engineering, 40: 3-9 (in Chinese).

[10] Jiang, D.E., Zhao, B.Y., Huang, H.Z., Xie, Y.C., Pan, G.C., Ran, G.P., Min, E.Z.. (2000). Dispersion of cobalt (II) phthalocyanine tetrasulfonate on active carbon. Appl. Catal. A, 192: 1-8.

[11] Hacıvelioğlu, F., Durmuş, M., Yeşilot, S., Gürek, A.G, Kilic, A., Ahsen, V. (2008). The synthesis, spectroscopic and thermal properties of phenoxycyclotriphosphazenyl- substituted phthalocyanines. Dyes Pigments, 79: 1423.

[12] Huang, J.L., Peng, Y.R., Chen, N.S. (2001). Some Spectrum Methods on the Structures of Metal Phthalocyanine. Spectrosc. Spect. Anal., 21: 1-6.

[13] Menini, L., Pereira, M.C., Ferreira, A.C., Fabris, J.D., Gusevskaya, E.V. (2011). Cobalt-iron magnetic composites as heterogeneous catalysts for the aerobic oxidation of thiols under alkali free conditions. Appl. $\mathrm{Ca}$ tal. A, 392: 151-157.

[14] Wallace, T.J., Schriesheim, A., Hurwitz, H., Glaser, M.B. (1964). Mercaptans in the presences of inorganic transition metal complex. Ind. Eng. Chem. Prod. Res. Dev., 3: 237-241.

[15] Ganguly, S.K., Das, G., Kumar. S., et al. (2012). Mechanistic kinetics of catalytic oxidation of 1-butanethiol in light oil sweetening. Catal. Today, 198: 246-251. 